\title{
EVOLUCIÓN DE LA POLÍTICA TURÍSTICA DE SINGAPUR (1965-2015) ${ }^{1}$
}

\author{
Alfredo Mena Navarro \\ Fernando Almeida García \\ Rafael Cortés Macías \\ Universidad de Málaga
}

\section{RESUMEN}

Singapur ha experimentado en los últimos 50 años un gran avance en términos turísticos y es un ejemplo de un destino con muchas limitaciones que ha logrado consolidar su liderazgo y ejercer una gran influencia en su entorno. En esta investigación se analiza la evolución de la política turística de Singapur mediante una adaptación del modelo de Airey y Chong (2011). Se parte de la premisa de que detrás de las decisiones y actuaciones tomadas en este ámbito hay una serie de factores externos e internos al sistema turístico que lo condicionan. Bajo esta perspectiva y a través de un análisis del contexto en el que se elabora la política turística se identifican las claves del éxito del modelo turístico de Singapur.

Palabras claves: política pública; Sudeste Asiático; desarrollo; contexto.

\section{Evolution of Singapore tourist policy (1965-2015)}

\section{ABSTRACT}

Tourism in Singapore is a major industry that has experienced significant advances in the last 50 years. This country stands out as an example of how a tourist destination with many limitations has managed to consolidate its leadership within its geographical area, i.e. Southeast Asia. Using an adaptation of the conceptual model of Airey and Chong (2011), this paper analyzes the evolution of the tourism policy in Singapore. According to this approach,

Recibido: 15 de febrero de 2017

Devuelto para su revisión: 4 de septiembre de 2017

Aceptado: 27 de noviembre de 2017

Departamento de Geografía. Universidad de Málaga. Campus de Teatinos, s/n. 29071 MÁLAGA (ESPAÑA): almenas60@yahoo.es, falmeida@uma.es,rcortes@uma.es

1 La investigación contiene avances de resultados de la tesis doctoral del primer autor en el marco del Doctorado en Turismo. 
the factors from outside and inside the tourism system influence the decisions and actions taken. By considering the tourism policy-making and implementation context, this study identifies the key elements of the Singapore tourism model success.

Keywords: public policy; Southeast Asia; development; context.

\section{INTRODUCCIÓN}

Singapur es una isla con un reducido tamaño $\left(719,1 \mathrm{~km}^{2}\right)$ situada en el extremo sur de la península malaya, limitando con Malasia e Indonesia. Su posición estratégica como centro del Sudeste Asiático despertó en el siglo XIX el interés de los británicos por establecer una colonia en este territorio.

\section{Figura 1 \\ LOCALIZACIÓN DE SINGAPUR}

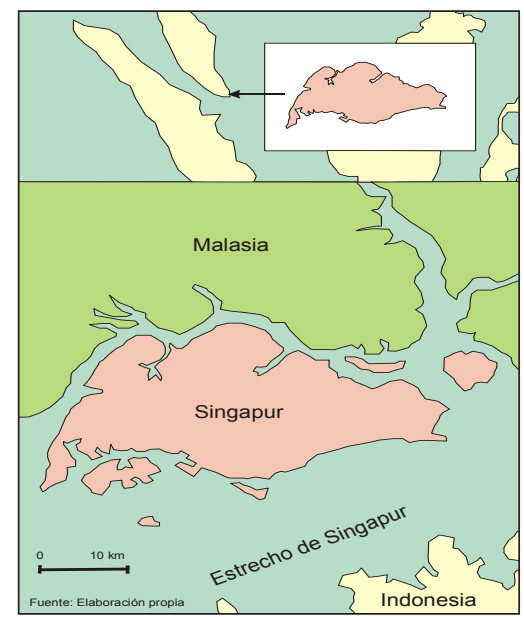

Fuente: elaboración propia.

El auge comercial alcanzado por la ciudad durante el período colonial hizo que se convirtiera en un lugar de paso y escala obligada de aquellos comerciantes que hacían la ruta entre Oriente y Occidente y en un cruce de caminos y culturas, con personas que empezaron a llegar procedentes de distintos lugares de Asia y del resto del mundo.

Su historia como estado independiente es reciente, comenzó en el año 1965 tras su proclamación como república. Los años que rodean este acontecimiento histórico fueron convulsos y llenos de problemas económicos, políticos y sociales que hicieron temer por la supervivencia de este país recién independizado. Su gobierno, controlado de forma férrea por el Partido de Acción Popular (que se ha mantenido en el poder hasta la actualidad) puso entonces en marcha un programa de desarrollo que cambió por completo la faz de la ciudad y sus cimientos económicos, sociales y culturales. 
De un país en vías de desarrollo en la década de los 60 del siglo XX emergió en poco tiempo otro con unos niveles de desarrollo sin parangón en el resto del Sudeste Asiático a pesar de las limitaciones derivadas de su tamaño, la alta densidad demográfica, la escasez de recursos naturales y la tensa relación con los estados vecinos. El turismo ha tenido en este proceso un papel relevante, siendo un área de notable interés por su impacto en la economía, la sociedad, la cultura, la política nacional e internacional y el paisaje urbano de Singapur.

La importancia concedida a esta industria por parte del estado ha generado un considerable volumen de estudios financiados por el sector público y privado con el fin de evaluar la situación del turismo en Singapur. Estos análisis han seguido lo que Scott (2011: 6) ha denominado "la perspectiva de la industria". Sin embargo, no ha sido tanta la atención prestada desde el ámbito académico. A grandes rasgos, las principales líneas de investigación y autores sobre el turismo en Singapur son los siguientes:

- Impacto económico (Heng y Low, 1990).

- Planificación, desarrollo y gestión del destino (Ern et al., 2002; Henderson, 2005; Teo y Chang, 1999; Wong, 1988).

- Marketing del destino (Chang, 1997).

- Turismo como fenómeno sociocultural y político (Leong, 1997; Ooi, 2001).

- Segmentos de mercado (Ganguli y Ebrahim, 2016).

El foco de interés de estas investigaciones se ha situado en cierto modo en las actuaciones llevadas a cabo en materia de turismo y su impacto en Singapur, siendo muy escasos los análisis de los factores que han influido en el proceso de formulación e implementación de la política turística. El estudio realizado por Henderson (2015), en donde se comparan las circunstancias externas que han condicionado el desarrollo de Singapur como destino turístico en dos períodos concretos es la excepción a esta dinámica.

Richter (1989: 11) señalaba que el éxito o fracaso del turismo es en gran medida producto de la acción política y administrativa, la cual está influenciada por los atributos locales (Hall, 2000; Pforr, 2005) y por las dinámicas y procesos globales (Dredge y Jamal, 2016). Teniendo presente esta perspectiva, este artículo de carácter descriptivo estudia la evolución de la política turística en Singapur entre 1965 y 2015 a partir del análisis de documentos oficiales. Se plantean, además, una serie de objetivos específicos:

(i) Averiguar la influencia que los factores externos e internos al sistema turístico han tenido en las decisiones y acciones tomadas en este ámbito.

(ii) Examinar las principales actuaciones del gobierno en materia turística y encuadrarlas en un contexto más amplio.

(iii) Identificar las claves que han otorgado singularidad al modelo turístico de Singapur y que han conducido a su éxito.

La principal aportación del mismo está en el hecho de ser el primer estudio específico en español de la política turística de Singapur, un país situado en una de las regiones más dinámicas del mundo, Asia Oriental, y que despierta un gran interés a nivel académico y 
científico. El estudio se trata de uno de los escasos análisis centrado en los factores que han influido tanto en el proceso de toma de decisiones en la política turística como en el producto de esas decisiones.

Para estructurar la discusión de una manera coherente, el artículo se ha dividido en tres apartados basados en las fases evolutivas que se han identificado en la política turística de Singapur (despegue, consolidación y madurez). A través de una perspectiva holística se exponen de forma cronológica en cada una de las fases, los inputs (factores internos y externos al sistema turístico) y los outputs (acciones y decisiones) de la política turística, siguiendo el modelo conceptual de Airey y Chong (2011).

\section{LA POLÍTICA TURÍSTICA COMO MARCO DE INVESTIGACIÓN}

El presente trabajo se inscribe dentro una línea de investigación que adquiere una mayor importancia entre los investigadores del turismo a partir de los 2000 (Airey, 2015) y que pone el foco de atención en los vínculos entre el entorno, el sistema político y los resultados e impactos de la política turística (Hall y Jenkins, 1995), es decir, en el proceso a través del cual ésta se desarrolla, ejecuta y modifica, y no tanto en el contenido de la misma (Dye, 2008).

La política turística es un campo de estudio complejo que ha sido abordado desde diferentes perspectivas: economía, ciencias políticas, administración pública, sociología, geografía, historia, derecho o psicología (Dredge, Jenkins y Whitford, 2011). Esta complejidad ha hecho que sea una actividad difícil de definir (Velasco, 2011). Una de las definiciones más extendida a pesar de su generalidad es la realizada por Hall y Jenkins (1995), según la cual la política turística es "[...] lo que los gobiernos eligen hacer o no con respecto al turismo" (p. 8). Esta propuesta, que coloca al gobierno en el centro de su análisis, ha sido matizada por otros investigadores como Dredge y Jamal (2015) que indican que "la política no puede ser entendida independientemente del aumento de la influencia empresarial, de los procesos de globalización, de la gestión pública neoliberal, de la gobernanza en red y de la asociación público-privada" (p. 5), es decir, de factores que van más allá del gobierno de un determinado país y que están relacionados con un contexto más amplio y dinámicas globales.

La diversidad de disciplinas que estudian la política turística ha favorecido asimismo que en este área de análisis se hayan aplicado teorías y conceptos muy diversos (Scott, 2011).

La teoría del sistema político de Easton (1965) es una de las que ha tenido mayor relevancia. Proveniente de la ciencia política, esta teoría ha sido tomada como referencia por numerosos investigadores (Hall y Jenkins, 1995; Airey y Ruhanen, 2011; Pforr, 2005) para explicar los procesos de la política turística y sus resultados. De acuerdo a la misma, el sistema político opera en un entorno dinámico en donde hay unos inputs (demanda y apoyos) y unos outputs (decisiones y acciones) que se retroalimentan (Easton, 1965).

Su aplicación al ámbito del turismo, realizada por primera vez por Hall (1994), ha supuesto una mayor atención a cuestiones relacionadas con los procesos de elaboración de las políticas turísticas, como los mecanismos institucionales, el poder, los actores, los intereses y los valores (Hall y Jenkins, 1995: 58) y ha generado modelos conceptuales que han servido de guía para este estudio. 
Voces críticas han señalado la naturaleza simplificadora de este tipo de modelos ante un fenómeno complejo y con muchos matices como es la política turística (Dredge y Jenkins, 2007). Pero a pesar de estas limitaciones, tal y como apunta Airey (2015), éstos han resultado muy útiles por su labor "[...] en la delimitación del espacio que abarca la elaboración de la política así como en la identificación de los procesos involucrados" (p. 247). Para evitar esta problemática, autores como Pforr (2005) o Bramwell (2011) han apostado por la combinación en sus investigaciones de varios enfoques metodólogicos y modelos conceptuales.

\section{METODOLOGÍA}

Como marco teórico para esta investigación se ha escogido el modelo conceptual de Airey y Chong (2011), que tiene como base la teoría del sistema político de Easton (1965). Aún siendo consciente de su tendencia a la simplificación, que puede ser entendida como una debilidad (Pforr, 2005), este modelo posibilita diseccionar procesos complejos como los que ocurren en la elaboración de la política turística (Airey y Ruhanen, 2014) y analizar el contexto desde una perspectiva más amplia y no tan centrada en el papel del gobierno.

De acuerdo al mismo hay unos factores externos e internos al sistema turístico (inputs) que interactúan (proceso) para generar unas decisiones y acciones (outputs).

\section{Figura 2}

\section{MODELO CONCEPTUAL}

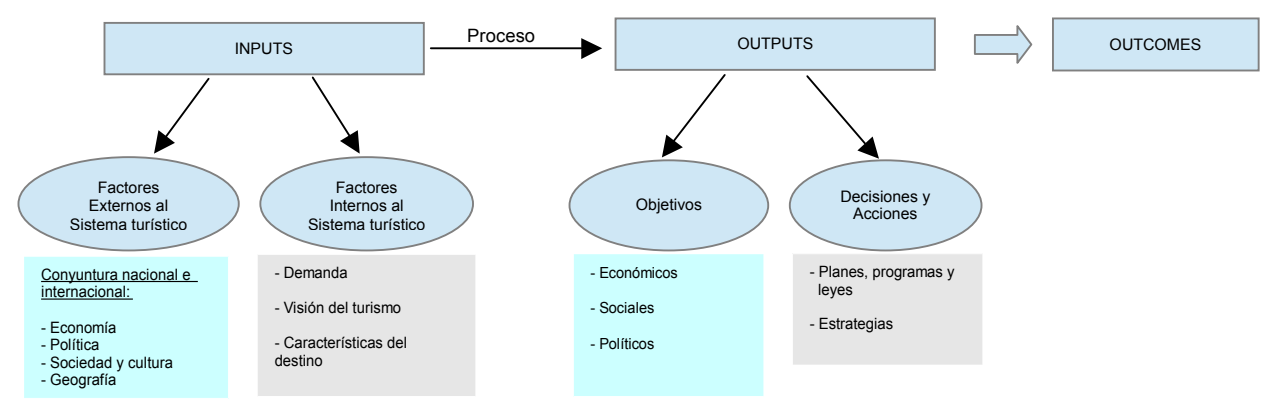

Fuente: Adaptado del modelo conceptual de Airey y Chong (2011).

Aunque el resultado de la política turística (outcomes), ya sea el esperado o el accidental como lo denomina Scott (2011), no es un objeto central de este estudio, es importante hacer referencia al mismo debido a que es también un elemento que influye en la elaboración e implementación de ésta.

El estudio de caso es el método de investigación más adecuado para el objetivo planteado en este artículo, ya que permite desarrollar una descripción densa y analizar aspectos menos tangibles de la política turística como la ideología o los valores, facilitando de esta manera una mejor comprensión de los procesos implícitos en este fenómeno (Stevenson, Airey y Miller, 2008: 734). La elección de Singapur como estudio de caso viene 
motivada por el éxito de su modelo de desarrollo turístico, caracterizado por un fuerte control del estado y muy globalizado, que ha hecho del país un destino líder en la región Asia-Pacífico y con gran influencia en su entorno geográfico $\left(11^{\circ}\right.$ posición mundial en el Índice de Competitividad de Viajes y Turismo de 2015). Se trata de un lugar único en el que confluyen una serie de factores locales e internacionales que hacen muy interesante la investigación de su política turística.

Figura 3

EVOLUCIÓN DE LA LLEGADA DE TURISTAS A SINGAPUR

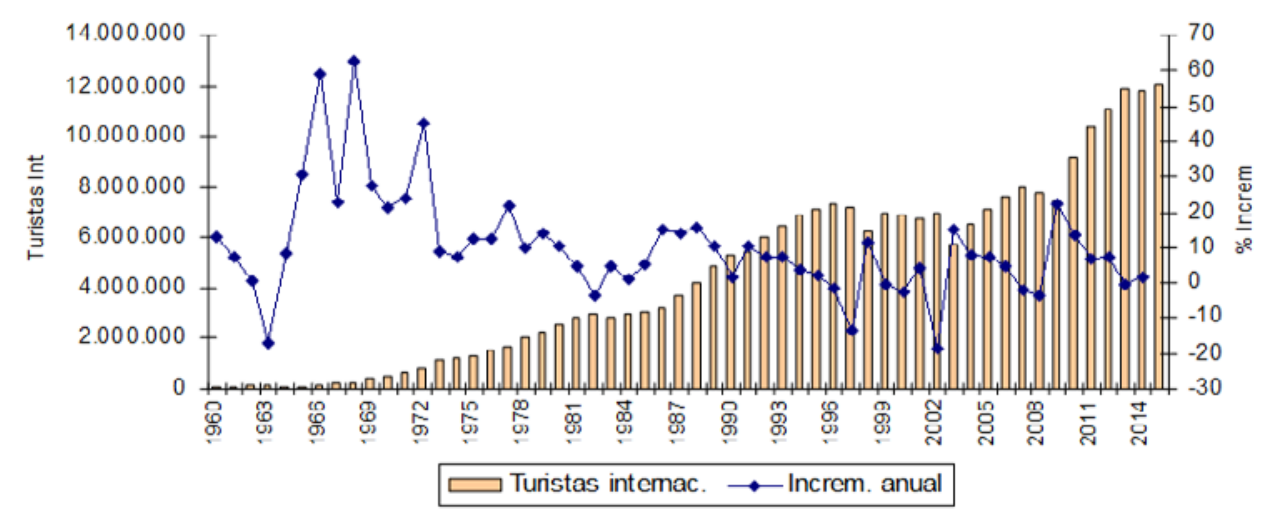

Fuente: Singapore Tourism Board.

Para el análisis de este fenómeno en el período comprendido entre 1965 y 2015, se plantean tres fases evolutivas:

1. Fase de despegue (década de los 60 y 70)

2. Fase de consolidación (década de los 80)

3. Fase de madurez (década de los 90 hasta el 2015)

El criterio seguido para esta clasificación se basa en el crecimiento de la actividad turística y su influencia en la agenda política de Singapur.

\section{Tabla 1 \\ ESTADÍSTICAS SOBRE TURISMO EN SINGAPUR EN EL PERÍODO 1965-2015}

\begin{tabular}{|l|c|c|c|c|c|c|}
\hline & $\mathbf{1 9 6 5}$ & $\mathbf{1 9 7 5}$ & $\mathbf{1 9 8 5}$ & $\mathbf{1 9 9 5}$ & $\mathbf{2 0 0 5}$ & $\mathbf{2 0 1 5}$ \\
\hline Llegada de visitantes & 98.481 & 1.324 .312 & 3.030 .970 & 7.137 .255 & 8.943 .029 & 15.231 .469 \\
\hline $\begin{array}{l}\text { Ingreso por turismo } \\
\text { (en millones de Euros) }\end{array}$ & 45,5 & 482,2 & $1.381,1$ & $7.392,7$ & $6.793,1$ & $13.747,5$ \\
\hline
\end{tabular}

Fuente: Heng y Low (1990) y Singapore Tourism Board. 
Dentro de cada fase se han identificado una serie de factores externos e internos al sistema turístico (inputs). El criterio de selección de estos elementos ha estado basado en el grado de influencia que el propio gobierno ha otorgado a los mismos en relación a la formulación e implementación de la política turística, dejando al margen otros que, aunque han tenido cierto influjo, han sido considerados menos relevantes. Asimismo, se han descrito las acciones y decisiones que estos factores han generado, estableciéndose una relación de causalidad.

Este estudio ha requerido, por un lado, una amplia búsqueda de datos procedentes de diversas fuentes: documentos oficiales (informes de Singapore Tourism Board, discursos, planes, leyes, etc), publicaciones del sector turístico (revistas especializadas, conferencias, etc.), prensa escrita y digital y literatura científica sobre el turismo en Singapur y la política turística en general, y por otro, una labor de trabajo de campo con la realización de 19 entrevistas semiestructuradas a actores claves del ámbito del sector MICE (acrónimo inglés de Meetings, Incentives, Conferences, Exhibitions, cuya traducción al español es Reuniones, Incentivos, Conferencias y Exhibiciones) y turístico de Singapur. Se ha de indicar que aunque estas entrevistas no han sido utilizadas específicamente para este artículo, sino que forman parte de una investigación más extensa, han proporcionado una visión y un conocimiento más completo y profundo de esta temática.

Los datos han sido analizados usando un análisis de contenido inductivo con la ayuda del software Atlas $T i$, que ha facilitado la identificación de temas centrales en la política turística de Singapur a partir de la codificación de la información proveniente de los documentos primarios y el establecimiento de vínculos entre los códigos registrados.

\section{FASE DE DESPEGUE (DÉCADA DE LOS 60 Y 70)}

El origen del turismo en la isla de Singapur está ligado a la presencia de los británicos en la misma, que construyeron en 1819 un puerto comercial que adquirió gran relevancia por su privilegiada situación geográfica. El dinamismo y exotismo de la colonia atrajo a viajeros pertenecientes a la aristocracia y clase alta europea. En esta época de gran auge comercial fueron construidos hoteles emblemáticos como el Raffles Hotel.

La convulsa primera mitad del siglo XX, sobre todo la ocupación japonesa durante la Segunda Guerra Mundial y el inicio del proceso de descolonización, trajo una enorme inestabilidad y un futuro lleno de incertidumbres para Singapur.

Tras alcanzar su autonomía total en 1959, los problemas económicos que venía padeciendo el país se agravaron y elevaron el desempleo a cuotas casi insostenibles. El gobierno surgido tras las primeras elecciones generales celebradas en ese mismo año vio la necesidad de poner en marcha un plan de industrialización para desarrollar la economía.

El turismo no fue considerado en este contexto un sector prioritario. El gobierno estaba más preocupado por otras cuestiones que creía más urgentes, como la vivienda o la industrialización (Wong, 1988). Lim (1979), citado en Hall y Oehlers (2000: 85) señalaba que a la cuestión de prioridad había que añadir otro tema para explicar esta falta de apoyo gubernamental. Según este autor, el partido político que asumió el poder, 
Partido de Acción Popular (PAP) no estaba muy convencido de los beneficios del desarrollo turístico por temor a que el turismo generara un proceso de erosión cultural.

A pesar de las medidas tomadas para atraer inversiones extranjeras en el sector secundario, el desempleo seguía en aumento al igual que las tensiones políticas y sociales. Por tanto, no quedó más remedio que mirar hacia otros sectores económicos, entre los que se incluía el turismo, que hasta ese momento había sido visto con cierto recelo.

1963 fue un punto de inflexión en la historia del turismo de Singapur. El primer hito que puso de manifiesto el cambio de mentalidad del gobierno con respecto a este sector fue el traspaso de las competencias en turismo del Ministerio de Cultura al Ministerio de Economía en enero de ese año por estar mejor preparado, financiera e intelectualmente, para desarrollar el turismo como una industria importante (Finance Ministry to handle tourism, 23 de enero de 1963).

1963 fue también el año en el que Singapur, Malaya, Sabah y Sarawak, colonias británicas que recién habían adquirido la autonomía total, formaron la Federación de Malasia oficialmente. Esta unión abrió grandes expectativas de negocio para Singapur y creó una magnífica oportunidad para desarrollar un programa de cooperación regional en el que Singapur pudiera funcionar como base desde donde los turistas visitaran otros lugares de la región.

Ante esta situación, el Ministerio de Economía lanzó un proyecto de ley para la creación de Singapore Tourist Promotion Board (STPB) el 28 de noviembre de 1963. Esta ordenanza entraría en vigor el 1 de enero de 1964 (National Library Board, 2015).

El ministro de Economía, Goh Keng Swee, fue el principal artífice de esta iniciativa tras identificar el turismo como un motor económico sin explotar en Singapur. Los argumentos que dio para defender su desarrollo fueron los siguientes: (i) La capacidad de la industria turística "para redistribuir la riqueza entre las naciones desarrolladas y en desarrollo de una manera digna y voluntaria" (National Archives of Singapore, 1964). Se trataba de un argumento de especial relevancia para un país en vías de desarrollo y que no quería depender de la ayuda humanitaria internacional para su supervivencia; (ii) La inversión necesaria para desarrollar el turismo era mucho menor que los ingresos y el empleo que generaría; (iii) Por último, consideraba que el turista podía convertirse en un efectivo embajador de Singapur. Este aspecto, en un contexto en el que se pretendía atraer inversión extranjera, era destacado ya que existía la necesidad de crear una imagen positiva en el ámbito internacional.

Con la creación de esta organización y el reconocimiento explícito de la contribución del turismo en la creación de empleo y en la generación de riqueza, el gobierno de Singapur se embarcó por primera vez en su historia en la misión de desarrollar y promocionar el país como destino turístico.

Los años 60 fueron años muy complejos, en los que a los graves problemas internos se unieron otros de carácter internacional con Indonesia y los frecuentes choques políticos con Malasia que acabaron con la expulsión de Singapur de la Federación y su proclamación como república independiente en 1965 (Lee, 2000)

Ante este panorama tan desalentador, la prioridad del gobierno en materia turística era desarrollar la industria para atraer inversión y crear empleo cuanto antes. Era necesario situar a Singapur en el mapa turístico y empezar a proporcionarle una marca internacional y de prestigio. 
La política turística de STPB en esta década estuvo basada fundamentalmente en el desarrollo de planes de comercialización y promoción en los que se vendían su localización estratégica y sus atractivos culturales como país multiétnico. El eslogan usado en estos años fue Instant Asia, con el que se quería "transmitir la idea de Singapur como un destino de vacaciones que combinaba las atracciones, los gustos y culturas de los principales grupos étnicos de Asia” (STB, 2014a: 38).

También fue destacable la realización de campañas de concienciación y educación a fin de desarrollar una conducta favorable hacia el turismo entre la población local, a la vez que eliminar de la sociedad aquellos comportamientos y actos considerados perjudiciales para la imagen que se quería proyectar del país. Estas acciones y estrategias estuvieron siempre circunscritas a los intereses e ideología del PAP y del primer ministro Lee Kuan Yew, que con una mezcla de autoritarismo, pragmatismo, intervencionismo y paternalismo controlaba de forma férrea el poder para lograr los objetivos propuestos y asegurar al mismo tiempo la supervivencia del régimen político instaurado (Henderson, 2014; Leong, 1997).

La década de los años 70 fue una etapa mucho más tranquila y de mayor estabilidad. El turismo fue uno de los sectores claves que ayudó a que el país comenzara a salir de esta situación de gravedad. Los pronósticos que vaticinaban la notable capacidad de la industria turística para generar empleo e ingresos se cumplieron, sobre todo a partir de 1969 que fue cuando se inició el despegue en las cifras de visitantes internacionales a Singapur y en los ingresos (Khan, Seng y Cheong, 1990). Se puede decir que en estas fechas se inició el turismo de masas en Singapur (Ver Tabla 1).

Los motivos de este crecimiento hay que buscarlos, por un lado, en una coyuntura internacional favorable (una creciente demanda turística de América, Europa y Australia hacia Asia por el mayor interés que despertaba este continente por la guerra de Vietnam, las mejoras de las comunicaciones aéreas, el abaratamiento del coste de los transportes y la consolidación de la cultura del ocio en el mundo occidental, que en este período era de donde procedía la mayor parte de los visitantes a Singapur) y por otro lado, a la intensa labor de STPB para que Singapur tuviera un peso cada vez mayor en el conjunto de visitantes que viajaban por el Sudeste Asiático. Esta organización, que en un principio estuvo bajo el ámbito de competencia del Ministerio de Economía, pasó a formar parte del Ministerio de Comercio e Industria cuando éste fue creado en 1979 (STPB, 1979), lo cual fue indicativo del relieve que estaba alcanzando el turismo en la economía de Singapur, al ser equiparado con otros sectores económicos claves del país.

Con el despegue del turismo a partir de 1969 fue necesario adoptar nuevos ejes de acción que complementaran la labor que se había venido realizando y que ayudaran a Singapur a convertirse en un destino turístico competitivo y con futuro ya que sus escasos recursos naturales e históricos lo situaban en desventaja con respecto a los países de su entorno geográfico.

En los 70 se puso en marcha una política de creación de atracciones e infraestructuras turísticas o relacionadas con el turismo, cuyo fin era atraer a más turistas de todos los mercados potenciales, así como inducirlos a alargar su estancia en Singapur. Para desarrollar estas acciones, la planificación fue esencial, especialmente en un país de tamaño muy limitado y con una población en constante crecimiento (Henderson, 2007). 
Singapur tenía, además, la particularidad de ser un estado de reciente creación e inmerso en un plan de desarrollo nacional que pretendía cambiar sus estructuras. De modo que la creación de nuevas atracciones e infraestructuras turísticas no fue un elemento aislado sino que estuvo estrechamente vinculado a otros aspectos de ese programa de desarrollo del gobierno (Soh, 1972), que en todo momento ejerció un fuerte control sobre el diseño, planificación y ejecución de esos proyectos (Ooi, 2002). STPB tuvo que trabajar y colaborar con otros organismos públicos para llevar a cabo estas actuaciones, en las que el estado no sólo invirtió una gran cantidad de dinero sino que actuó también como catalizador de la inversión privada (Henderson, 2014).

\section{Figura 4 \\ IDENTIFICACIÓN DE FACTORES EXPLICATIVOS DE LA POLÍTICA TURÍSTICA EN LA FASE DE DESPEGUE}

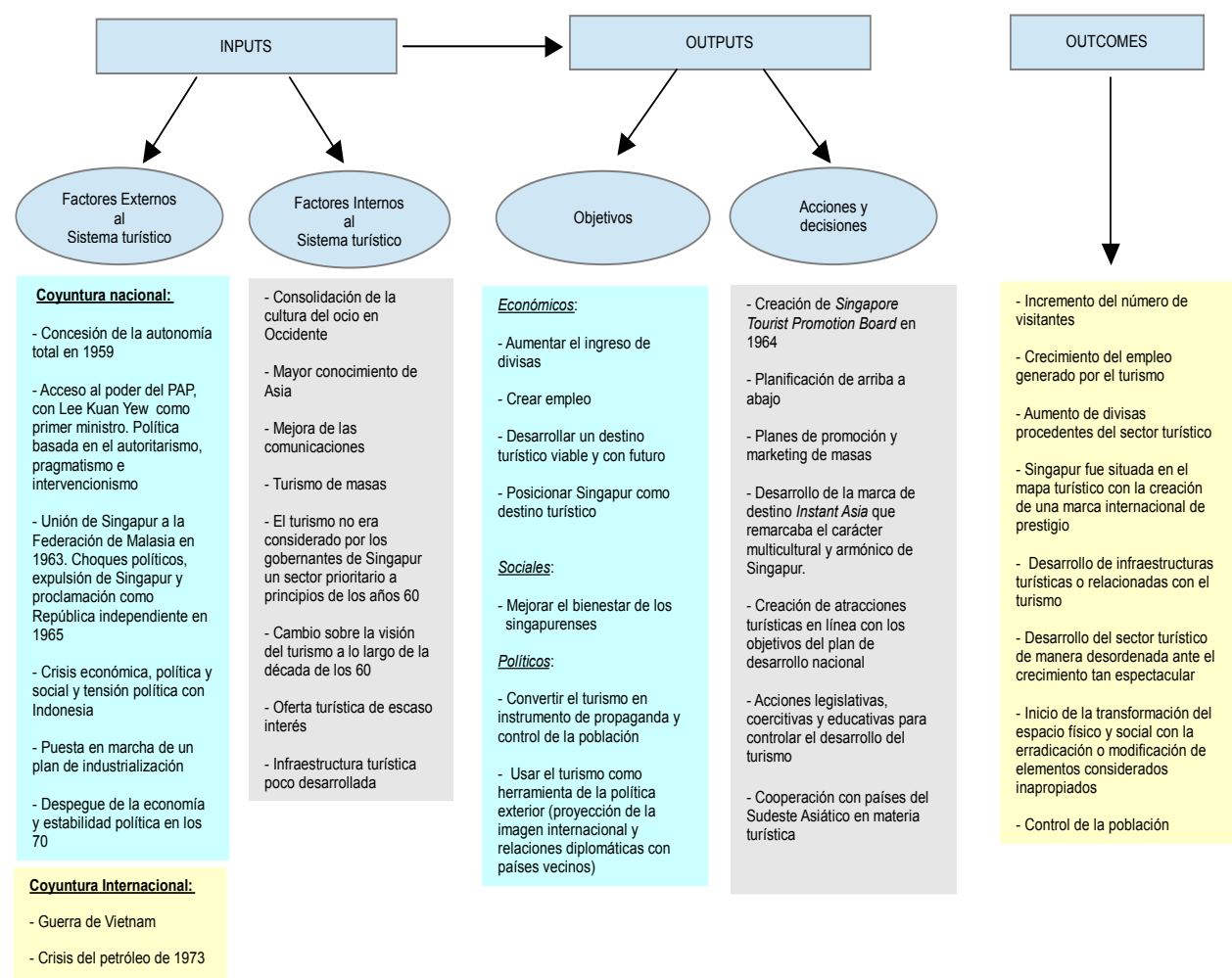

Fuente: elaboración propia.

En esta fase de despegue del turismo en Singapur, que tuvo como hito principal la creación de STPB en 1964, se establecieron, por consiguiente, las bases de su industria turística y quedaron ya entonces definidos algunos de los ejes de acción en la política turística desarrollada en las siguientes décadas (Ver Figura 4). 


\section{FASE DE CONSOLIDACIÓN (DÉCADA DE LOS 80)}

La década de los 80 se iniciaba con tranquilidad y optimismo, con un sector turístico fuerte y cada vez más consolidado, que representaba en 1980 el 8,5\% del Producto Interior Bruto de Singapur y aportaba el 7,9\% del empleo generado en el país (Khan, Seng y Cheong, 1990).

El gobierno de Singapur en su Plan de Desarrollo Económico de 10 años, elaborado en 1981, identificó al turismo como uno de los pilares del crecimiento del país en los 80, junto a otros sectores como la manufactura, el comercio, el transporte o las comunicaciones (The Ten-Year Plan, 7 de marzo de 1981)

Sin embargo, conforme avanzaba la década, surgieron problemas y retos inesperados en el turismo que hicieron saltar por primera vez la alarma y tambalear un sector que era ya fundamental en la economía de Singapur. La caída de un 3,5\% en el número de llegadas internacionales en 1983 fue un punto de inflexión en su política turística (STPB, 1984a). Por primera vez en la historia reciente del país, la industria turística se enfrentó a una crisis que no dependía en exclusiva de la situación internacional, sino que sus causas derivaban de problemas estructurales que arrastraba el destino y a los que no se había prestado la atención adecuada, tales como:

(i) La alta dependencia de pocos mercados emisores. Las principales áreas geográficas emisoras de turistas a Singapur eran: Estados Unidos, Reino Unido y Australia, que estaban atravesando un período de inestabilidad económica desde la crisis del petróleo de 1973, y los países del Sudeste Asiático, en donde fueron adoptadas medidas disuasorias para que sus ciudadanos no viajaran al exterior y con ello potenciar el turismo nacional (The Straits Times says...Wish you were here, 30 de septiembre de 1983)

(ii) La pérdida de competitividad frente a destinos más económicos y con más atractivos turísticos (Lee, 2004). Singapur se convirtió en un destino caro con una oferta turística escasa y débil que empezaba a no cumplir con las expectativas de una demanda más exigente, diversa y mejor informada en un contexto de transición del modelo turístico.

(iii) El proceso de modernización y transformación urbanística en el que estaba inmerso Singapur estaba provocando, además, que la imagen proyectada en la comunicación turística fuera distinta a la nueva realidad del país.

Esta situación creó un cierto pánico en el gobierno que, consciente de los problemas que podría acarrear esta crisis tanto a nivel económico como político, actuó con rapidez para solventar esta inestabilidad. En 1984 creó un comité de expertos para evaluar la situación del turismo y hacer recomendaciones (STPB, 1984b). El informe elaborado por este comité fue el primero y quizás el más significativo de una serie de estudios realizados en este período, y que sirvieron de base sobre la que se sustentaría la política turística de Singapur a lo largo de esta década.

Una vez detectadas las causas estructurales que lastraban el sector turístico fue el momento de pasar a la acción. El gobierno destinó en 1986 mil millones de dólares de Singapur (SG\$) a la implementación de un plan de desarrollo de productos turísticos, que 
estaría basado en cinco ejes temáticos: Exótico Oriente, Patrimonio colonial, Isla tropical, Ciudad-jardín limpia y verde, Eventos deportivos internacionales. El objetivo era convertir a Singapur en un destino capaz de satisfacer las necesidades particulares de los mercados emisores tradicionales y a la vez atraer a visitantes procedentes de nuevos mercados (STPB, 1987). Se trataba de consolidar y diversificar. Este ambicioso plan necesitaba la participación del sector privado para su consecución, y por este motivo el estado puso en marcha su maquinaria para atraer la inversión privada. El papel desempeñado por STPB en este proceso fue clave ya que actuó como catalizador y coordinador de la iniciativa pública y privada.

Fueron numerosas las actuaciones en materia turística o relacionadas con el turismo iniciadas en los 80, que tras su finalización, transformaron de manera radical el espacio físico e incluso social de Singapur, crearon el ecosistema idóneo para la supervivencia del sector en el futuro e influyeron de forma significativa en la imagen de Singapur proyectada al exterior. Entre las actuaciones más llamativas realizadas por STPB estuvieron aquellas relacionadas con la intervención urbana directa, en colaboración con otros departamentos gubernamentales, para la conservación y puesta en valor de áreas históricas de la ciudad de carácter étnico (Chinatown, Little India, Kampong Glam y Emerald Hill) y del período colonial (Teo y Huang, 1995; Wong, 1988). Además se llevó a cabo también una intensa campaña de promoción turística internacional en torno al eslogan Surprising Singapore con el que se quería transmitir la idea de un país moderno con una rica diversidad de tradiciones étnicas (Leong, 1997).

Los esfuerzos económicos e institucionales realizados y el fuerte hincapié dentro de la política turística en aspectos como la planificación, el marketing más focalizado y agresivo, el desarrollo de productos turísticos acorde con la demanda, la formación, la colaboración público-privada y la cooperación regional comenzaron a dar sus frutos y a partir de 1987, la tasa de crecimiento en el número de llegadas de turistas volvió a niveles anteriores a la crisis, quedando de este modo fortalecido este sector.

En todas estas acciones se repitieron una serie de pautas que ya venían poniéndose en práctica con anterioridad y que iban más allá del ámbito estrictamente económico, quedando demostrado que el turismo en Singapur era también un instrumento útil a los intereses e ideología de los gobernantes, con Lew Kuan Yew a la cabeza:

(i) El control del gobierno para que los proyectos, aunque fueran privados, siguieran las líneas y directrices marcadas por él.

(ii) Utilización del turismo como justificación para intervenir en el paisaje urbano y social de Singapur en base a una mentalidad e intereses específicos y que estaban en relación con el proceso socio-político vigente de control de la población por parte del estado (Leong, 1997: 81).

(iii) El desarrollo de productos turísticos que fueran compatibles con los intereses de los turistas y de la población local (Ooi, 2002).

Esta etapa de consolidación del turismo en Singapur supuso, en definitiva, la ordenación de un sector que adolecía de problemas estructurales por su rápido crecimiento en las décadas anteriores. La puesta en marcha del Plan de Desarrollo de Producto Turístico (1986-1991) fue la confirmación de la importancia que iba adquiriendo el turismo en la agenda gubernamental (Ver Figura 5). 


\section{Figura 5 \\ IDENTIFICACIÓN DE FACTORES EXPLICATIVOS DE LA POLÍTICAS TURÍSTICA EN LA FASE DE CONSOLIDACIÓN}

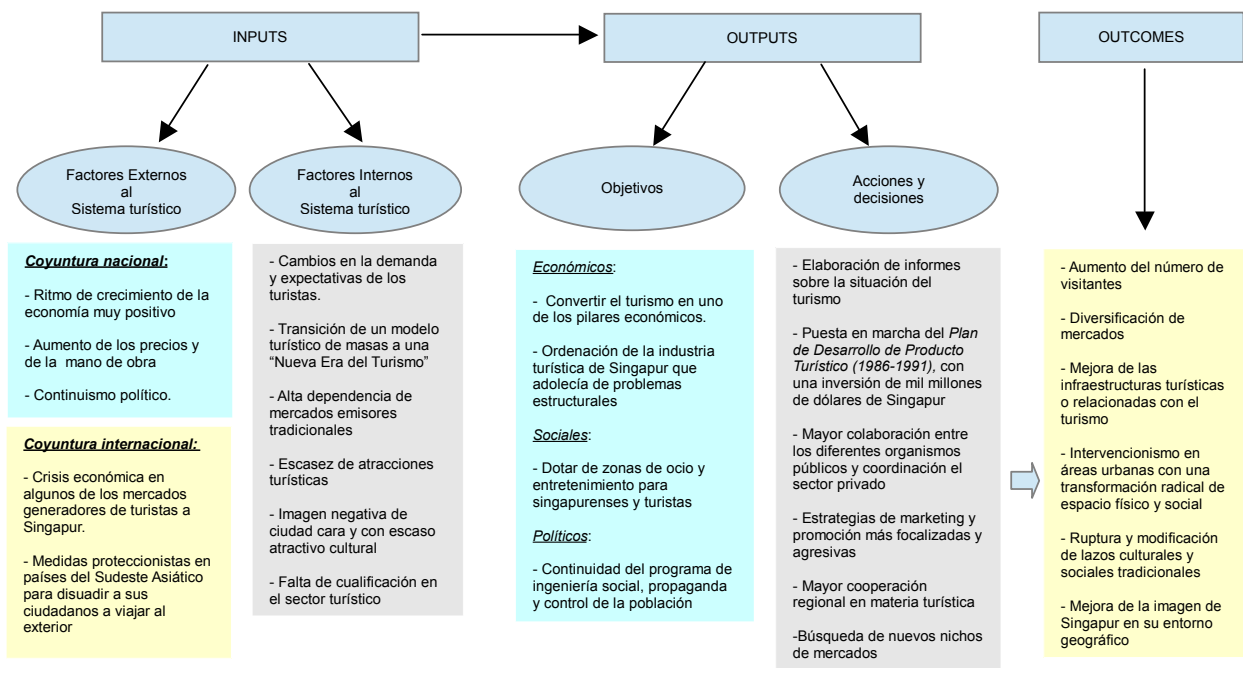

Fuente: elaboración propia.

\section{FASE DE MADUREZ (DÉCADA DE LOS 90 Y LOS 2000)}

Debido a la complejidad de esta fase se ha optado por la subdivisión en dos apartados de la misma en base a los datos de crecimiento del sector (Ver Figura 3) y a la influencia de dos factores considerados claves en la formulación e implementación de la política turística: la internacionalización del sector turístico y la búsqueda de la calidad.

\subsection{Internacionalización del sector turístico (década de los 90)}

La década de los 90 se inició con un sector turístico robustecido y fue el inicio de una nueva etapa en la historia del turismo del país, con cambios sustanciales en las estrategias y forma de entender esta industria. El turismo se había convertido en una parte fundamental de la economía de Singapur, siendo ampliamente reconocida su capacidad para generar riqueza y mejorar la calidad de vida de la población.

Al impacto que la coyuntura internacional tuvo en la política turística de Singapur en los 90, con el estallido de la Guerra del Golfo Pérsico en 1991 y la grave crisis financiera asiática de 1997, se unieron dos factores que fueron determinantes en la forma en la que el turismo comenzó a ser concebido en el país a partir de este momento.

Por un lado, los cambios sociodemográficos y de hábitos de los turistas y el uso de las nuevas tecnologías provocaron la aparición en los años 90 de lo que Fayos-Solá (1996) denominó una "Nueva Era del Turismo", en la que hubo que explorar nuevas estrategias en la promoción y el marketing y en el desarrollo de productos turísticos para atender a la multitud de intereses de los visitantes. 
Por otro lado, a un nivel local, Singapur andaba inmersa en esta década en un proceso de conversión e internacionalización de su economía, en el que el turismo no quedó al margen. Ante la evidencia que existía sobre las limitaciones de espacio y de recursos para crecer y la creciente competencia de otros países, el gobierno apostó por la regionalización, es decir, el aprovechamiento del potencial de la región para convertir al país en el centro económico del Sudeste Asiático.

Esta visión, que fue aplicada al turismo, dio lugar a la puesta en marcha de una estrategia denominada Tourism Unlimited, que estaría, a la vez, en la base del plan estratégico lanzado en 1996 Turismo 21. Este plan perseguía la transformación de Singapur en la capital del turismo de la región Asia-Pacífico, en un destino de obligada visita para aquellos que viajaran a esta parte del mundo y en un lugar ideal para hacer negocios o inversiones relacionadas con el sector turístico (STPB, 1996). Se produjo, por tanto, una redefinición del concepto de turismo, que ya no quedó limitado únicamente al ámbito de la comercialización y promoción del destino sino que también empezó a ser visto como una industria con derecho propio para atraer inversiones y generar nuevas oportunidades de negocios.

Estos factores fueron decisivos en el diseño de la política turística y en el papel otorgado a STPB, que pasó a denorminarse Singapore Tourism Board (STB) en 1997 para ajustarse de forma más adecuada a las nuevas funciones adquiridas, vinculadas con los negocios y la regionalización (STB, 1998).

Los ejes estratégicos adoptados fueron en parte continuistas con respecto a la década anterior, pero perfeccionados para hacer frente a esos nuevos desafíos y retos, y en donde se quiso, además, proyectar hacia el exterior e interior una imagen más acorde con la nueva realidad de Singapur y la visión de su gobernantes.

Tras 11 años en uso de la marca Surprising Singapore, una nueva marca de destino fue lanzada en 1996 con el nombre New Asia-Singapore. El mensaje proyectado en este eslogan incidía de nuevo en el carácter multicultural y tradicional de Singapur, pero también ponía énfasis en la idea de modernidad, dinamismo y progreso dentro de un contexto que no quedaba reducido a las fronteras estrictamente nacionales, sino que representaba a Singapur como punta de lanza y parte integrante de un área geográfica más amplia, Asia, que estaba viviendo una transformación profunda, fruto del desarrollo económico y que estaba dando lugar a una nueva realidad única en el mundo. New Asia-Singapore recogía el espíritu y mentalidad oficial imperante en este período y respondía de manera eficaz a los intereses del partido político en el poder (Chang y Huang, 2005).

Bajo esta perspectiva, hubo una reformulación del producto turístico de Singapur, con el diseño de un marketing más concreto y el desarrollo de productos dirigidos a nichos de mercados considerados prioritarios para el país como el sector MICE. En general, hubo en esta etapa un cambio en la manera de enfocar el desarrollo de las atracciones turísticas con el objetivo de crear un producto completo capaz de ofrecer experiencias únicas y memorables, en un contexto caracterizado por la segmentación de mercados y por la gran diversidad de intereses existentes (Ooi, 2001).

También fue destacable el intento de configuración de un nuevo espacio turístico que no quedaba ahora confinado a las fronteras geográficas de Singapur sino que integraba 
el territorio de sus países vecinos a través de diversos acuerdos de colaboración, que al mismo tiempo ayudaron a mejorar las relaciones con esos países limítrofes y facilitaron la entrada de capital singapurense en los mismos.

Otra línea de actuación importante estuvo enfocada a la captación de inversiones de empresas turísticas internacionales y al fomento y desarrollo de la industria turística local. Con estas medidas se perseguía enriquecer la oferta de Singapur y crear nuevas oportunidades de negocios.

En definitiva, Singapur quiso aprovechar el potencial del turismo en todas sus facetas y siguió una serie de pautas que venían repitiéndose desde años anteriores para garantizar el liderazgo del país como destino turístico y asegurar que el desarrollo de este sector siguiera las líneas estratégicas marcadas por el propio gobierno, que aún seguía controlado por el PAP: la planificación de "arriba a abajo", la importancia concedida a la investigación y al análisis, el pragmatismo, la capacidad de reinvención y de ser útil al mundo y el fuerte intervencionismo y control estatal.

Todos estos elementos fueron claves en el éxito de este modelo turístico que empezaba a tener una gran influencia en el desarrollo de otros destinos asiáticos.

\subsection{Búsqueda de la calidad (década de los 2000 hasta el año 2015)}

La industria turística de Singapur entró en el nuevo milenio con una fortaleza mayor de lo que un primer momento se esperaba por la rápida recuperación de la crisis económica de Asia de finales de la década de los 90. Esta nueva etapa se inició con cierto optimismo.

En el año 2000 se hizo una revisión del plan estratégico Turismo 21 para adaptar el producto turístico de Singapur a las necesidades cambiantes de los turistas y generar nuevas oportunidades de negocio (STB, 2000).

Sin embargo, el optimismo inicial quedó pronto empañado por una serie de acontecimientos internacionales que pusieron de relieve la dificultad cada vez mayor de los países para protegerse del impacto de las adversidades políticas, económicas o naturales como consecuencia de la globalización.

Los atentados del 11 de septiembre de 2001 en Nueva York, el estallido de la Guerra del Golfo en 2003 y sobre todo la epidemia de neumonía asiática o también conocida por sus siglas en inglés SARS (Severe Acute Respiratory Syndrome) en este mismo año exigieron de nuevo una actuación rápida y eficiente para contrarrestar los efectos negativos que estaban trayendo al sector turístico de Singapur. Las estrategias adoptadas por STB para responder a esta delicada situación pasaron por la puesta en marcha de programas de marketing y promoción destinados a mejorar el posicionamiento de Singapur en mercados emergentes como China e India que estaban generando un volumen de turistas muy elevado, por el lanzamiento de iniciativas para captar y consolidar segmentos de mercado específicos y con gran proyección de futuro como el turismo MICE, educativo o de salud y por una colaboración más estrecha con las países de la región.

El éxito de estas medidas fue inmediato y el turismo en Singapur volvió a la senda de la recuperación y el crecimiento a partir de 2004, y así continuó hasta el fin de la década, sin grandes sobresaltos. 
Una vez superados estos escollos, fue el momento de analizar la situación del turismo en el país, sobre todo por los retos que ya se intuían por el crecimiento económico tan espectacular de otros países del Sudeste Asiático, el cual tenía una cara y una cruz para el sector turístico de Singapur. La parte positiva era que la mejora de la economía de estos países estaba permitiendo la aparición de una generación con altos niveles educativos y muy conectada con el exterior, que se caracterizaba por un interés en los viajes y por conocer y experimentar otros lugares y culturas (STB, 2014b). Pero también este hecho estaba haciendo que los gobiernos invirtieran cada vez más en la construcción y mejora de sus infraestructuras para consolidar a sus respectivos países como destinos turísticos. La competencia iba en aumento y Singapur empezaba a perder parte de su cuota de mercado en la captación de turistas en la región de Asia-Pacífico.

Este panorama obligó a la adopción en 2004 de una marca de destino diferente para comercializar y promocionar Singapur en el exterior, que fue llamada Uniquely Singapore. Esta nueva marca era en parte continuista con respecto a algunas de las imágenes y mensajes que New-Asia Singapore había proyectado con anterioridad (Henderson, 2007). Sin embargo, presentaba también puntos novedosos y diferentes para responder de forma más eficaz a los retos del turismo. Las referencias a Asia disminuyeron en la comunicación de esta marca, la cual resaltaba el carácter singular del país frente a sus vecinos. Singapur tenía necesidad de diferenciarse y de ser única en su entorno ante a esa creciente y cada vez más agresiva competencia.

En el año 2005 el gobierno lanzó un nuevo plan turístico denominado Turismo 2015 que buscaba revertir esta tendencia de pérdida de cuota de mercado (STB, 2006). Dentro de este plan se continuó con la estrategia de reinvención del paisaje turístico y la apuesta por ofrecer un producto innovador y diferenciado con respecto a sus competidores. Entre los proyectos más destacados y que mayor repercusión tuvieron, por las sinergias turísticas y económicas generadas, fueron la apertura en el 2010 de dos resorts integrados (Marina Bay Sands y Sentosa Resorts World) que consistían en dos mega complejos con casinos, hoteles, centros comerciales y centros de exposiciones y congresos, y la celebración de eventos de gran impacto mediático como el campeonato de Formula 1.

Al impacto positivo que supuso la creación y mejora de la oferta turística en el aumento de las cifras de visitantes se unió a partir del 2010 otro factor que contribuyó igualmente a este crecimiento: el incremento de los viajes interregionales motivados por el dinamismo económico de Asia y por el aumento de los vuelos de bajo coste y la mejor conexión de ciudades secundarias asiáticas con Singapur (Ver Tabla 1)

No obstante, en estos años se produjeron una serie de acontecimientos internacionales, que aunque su impacto en el sector turístico de Singapur no fue demasiado relevante, sí que provocaron cierto desconcierto, como la crisis económica europea, el terremoto y tsunami de Japón, las conflictos políticos en Tailandia o la pandemia de gripe aviar, que obligaron de nuevo a tomar medidas concretas.

Los retos a los que se enfrentaba la industria turística en esta nueva década en la que los cambios se sucedían de manera veloz como consecuencia de las nuevas tecnologías y de la globalización provocaron la necesidad de perfeccionar y rediseñar las acciones desarrolladas hasta el momento. 


\section{Figura 6 \\ IDENTIFICACIÓN DE FACTORES EXPLICATIVOS DE LA POLÍTICA TURÍSTICA EN LA FASE DE MADUREZ}

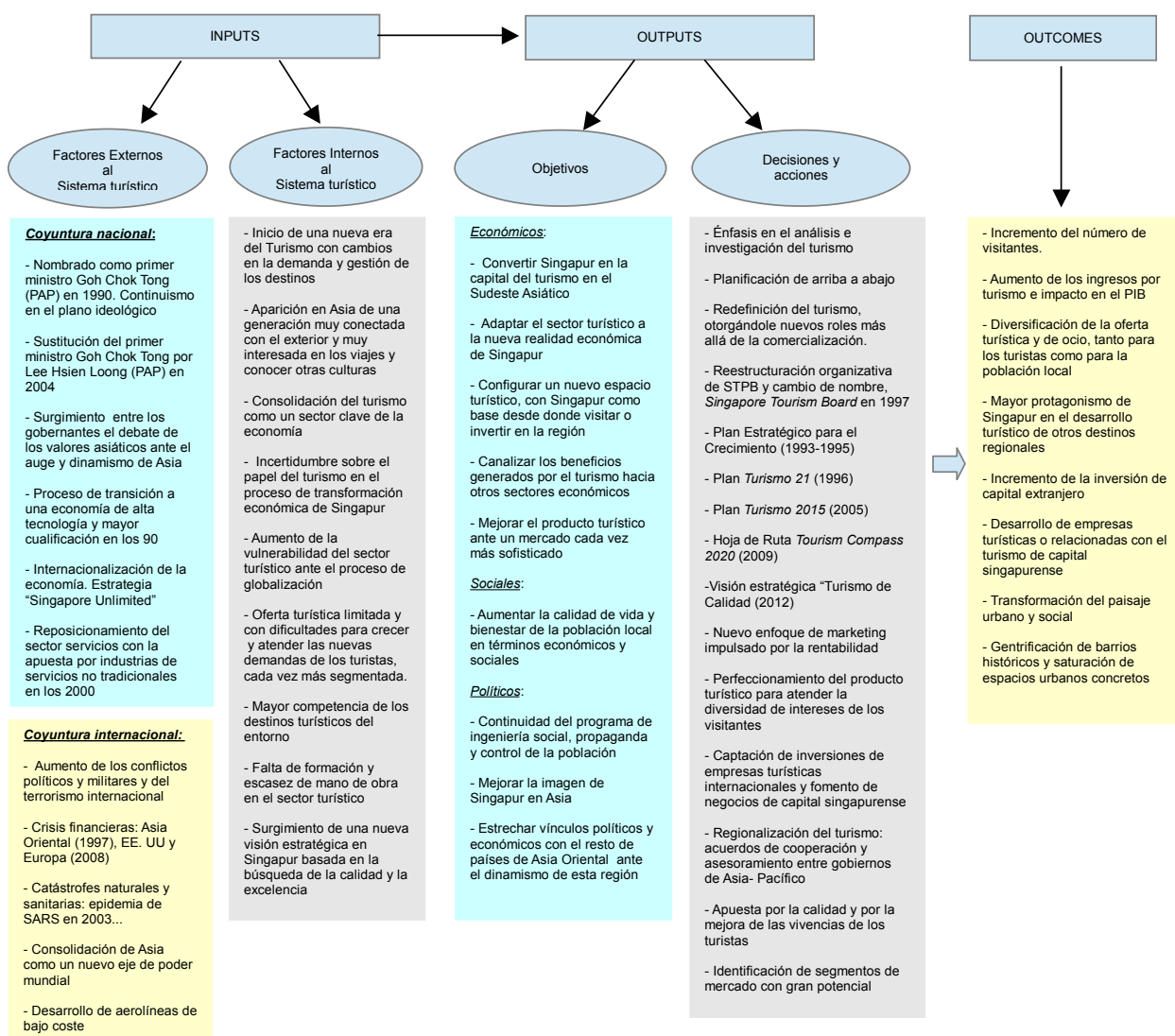

Fuente: elaboración propia.

En este sentido, la marca de destino Uniquely Singapore, que estuvo tan sólo en vigor 5 años, fue sustituida por otra nueva en el año 2010. Su pérdida de efectividad derivaba de que ya no respondía a los intereses de Singapur para ser comercializada ante una demanda hipersegmentada. La nueva marca fue llamada YourSingapore, que pretendía proyectar aspectos como la personalización, innovación y futuro (STB, 2014a).

Otro actuación reseñable fue la elaboración de una nueva hoja de ruta, Tourism Compass 2020, que condujo a la adopción en 2012 de una visión que perseguía un turismo de calidad (STB, 2009 y 2013a) para “[...] navegar en el cada vez más complejo panorama turístico por enfrentarse Singapur a viajeros más exigentes, por una intensificación de la competencia regional, por un crecimiento más lento de la mano de obra y por un impacto mayor del turismo sobre el medio ambiente." (STB, 2014a: 54). La búsqueda de la calidad implicó las siguientes acciones y estrategias: 
(i) El desarrollo de un nuevo enfoque de marketing impulsado por las ganancias (STB, 2013b).

(ii) La concesión de una menor importancia a la cooperación en materia turística con otros países de la región puesto que se pretendía que los turistas prolongaran su estancia lo máximo posible en Singapur en vez de en otros destinos regionales.

(iii) La creación de productos turísticos sofisticados, vanguardistas, distintivos y centrados en las experiencias y emociones y la necesidad de mejorar el servicio.

En definitiva, esta fase pone de relieve la existencia de un sector cada vez más consolidado y maduro, pero también más vulnerable a los efectos de la globalización por su alta dependencia del mercado internacional. La internacionalización y la calidad han sido los dos ejes principales en las que ha pivotado la política turística de este período (Ver Figura 6).

\section{REFLEXIONES FINALES}

Singapur es un ejemplo de cómo un país con recursos limitados ha logrado transformarse en un período corto de tiempo en un destino turístico muy competitivo y con gran influencia en su área geográfica, el Sudeste Asiático. Esta historia de éxito está vinculada no sólo a la existencia de ciertos elementos externos al sistema favorables al mismo, como el desarrollo del turismo internacional, sino también al diseño e implementación de una política turística que a lo largo de las distintas fases identificadas (despegue, consolidación y madurez) ha respondido a factores y dinámicas locales e internacionales: el sistema político, el marco económico, el contexto territorial, la globalización, etc.

El estudio de la política turística de Singapur revela que ésta no puede ser separada de su contexto (Henderson, 2015) puesto que se trata de una actividad enmarcada en un espacio y tiempo concretos e influenciada por factores externos e internos al propio sistema turístico (Lawrance y Dredge, 2007; Airey y Chong, 2011) que interaccionan unos con otros.

Bajo esta perspectiva, el análisis de los vínculos entre el entorno y la política turística ha sido fundamental para entender las claves del éxito de su modelo de desarrollo turístico, en donde se ha repetido una serie de patrones y pautas de acción que le han otorgado singularidad.

El turismo en Singapur se ha distinguido por una fuerte intervención del estado en todos los aspectos relacionados con el mismo. Este hecho está en estrecha relación con el sistema político surgido tras la independencia del país en el que un único partido político, el PAP, ha permanecido de forma continuada en el poder hasta la actualidad y ha ejercido su liderazgo e influencia en todas las esferas de la nación, favoreciendo el desarrollo de una política caracterizada por el fuerte control y el autoritarismo (Hall y Oehlers, 2000; Henderson, 2014). Esta forma de entender el poder se ha materializado en un desarrollo y planificación del destino de arriba a abajo y en la asignación al STB de funciones que han ido más allá de lo turístico, incluyendo acciones económicas, urbanísticas, educadoras de la población o captación de inversiones. 
El diseño e implementación de la política turística han estado en todo momento supeditados a los objetivos económicos, sociales o políticos considerados prioritarios por los gobernantes. Si en la fase de despegue el turismo fue concebido como una herramienta de desarrollo económico, la propia evolución del país y la necesidad de supervivencia de su régimen político hicieron que muy pronto se le considerara también una herramienta útil de control de la población, de propaganda y de proyección de una determinada imagen a nivel local e internacional (Leong,1997; Ooi, 2001; Henderson, 2015). El marco institucional ha impregnado en Singapur todos los aspectos de su política turística.

No obstante, esta investigación, en línea con lo afirmado por Dredge y Jamal (2015), pone también de relieve la interacción en el país de otros elementos y dinámicas locales y globales que han escapado al control del gobierno y que han tenido una gran influencia en la construcción de esa política, como el neoliberalismo o los procesos de globalización.

El marco económico, nacional e internacional, ha sido igualmente un factor determinante en la evolución del sector turístico de Singapur, que se ha tenido que amoldar en cada etapa a la lógica económica del momento. En este sentido, como ya se ha comentado, el turismo fue considerado en la fase de despegue un instrumento eficaz para salir de la grave crisis socioeconómica que atravesaba el país por su capacidad para generar empleos y atraer inversiones. Posteriormente, la exigencia de un cambio en el modelo productivo, sobre todo en la fase de madurez, trajo consigo una redefinición del concepto de turismo en donde el foco se colocaba en la búsqueda de la internacionalización y la apuesta por la calidad.

Por otro lado, Singapur se ha caracterizado por el desarrollo de un modelo turístico fuertemente globalizado y muy dependiente de la demanda internacional, siendo reducida la nacional. A pesar de haberse construido una imagen turística de destino eficiente, seguro y atractivo para las compras, los negocios o el juego, la demanda ha sufrido a lo largo de las distintas fases fuertes oscilaciones y cambios. El hecho de ser un lugar tan sensible al impacto de la globalización y la coyuntura internacional ha provocado que desde muy pronto se hayan tenido que diseñar acciones y estrategias (Plan de Desarrollo de Producto Turístico 1986-1996; Turismo 21, etc.) que han perseguido una reinvención continua del destino (Teo y Chang, 2000) para adaptarlo de forma rápida y eficaz a los nuevos tiempos, a las nuevas tendencias y a los imprevistos de diversa índole, mostrando en todo momento su capacidad de adaptación a las diferentes circunstancias.

Asimismo, la creciente competencia de otros países del Sudeste Asiático, que no tienen las limitaciones de espacio de Singapur para crecer y que cuentan con mayores recursos, ha ido también creando y agudizando la necesidad del país por mantener una oferta competitiva y cumplir con las expectativas de la demanda, cada vez más exigente y segmentada, especialmente en la última etapa. Frente a estos hechos, Singapur se ha revelado como un destino innovador y pionero en cuanto a su oferta turística (atracciones y espacios de ocio, hoteles, resorts integrados, eventos, etc.) y estrategias de promoción, anticipándose a sus competidores.

La planificación, la adaptabilidad, el pragmatismo, la innovación y la rapidez en la búsqueda de soluciones antes los cambios y retos han sido, por tanto, elementos presentes en la política turística de Singapur y que se han mantenido a lo largo del tiempo para asegurar la supervivencia y éxito de su modelo de desarrollo turístico. 
En conclusión, la interpretación que se puede hacer de la política turística de Singapur en función del análisis realizado de los propios documentos del gobierno es que ésta es un proceso y un producto de su contexto. Este aspecto añade complejidad al análisis de este fenómeno en el sentido de que cada país tiene una dinámica diferente (Hall y Jenkins, 1995), que dificulta el establecimiento de modelos universales preestablecidos. En cualquier caso, hay algunos elementos comunes en los instrumentos políticos usados en otros destinos (Scott, 2011) y en la propia dinámica turística. Para una futura investigación sería interesante realizar algún estudio comparativo de la política turística de Singapur con otros países o regiones próximas o con características similares, como son los casos de Hong Kong o Corea del Sur. Ello permitiría una visión global de los procesos transnacionales que afectan al turismo (Almeida-García, 2014) y una mayor información sobre la respuesta dada por cada uno de los gobiernos nacionales frente a retos globales.

\section{BIBLIOGRAFÍA}

AIREY, D. (2015): «Developments in understanding tourism policy», Tourism Review, vol. 70, no 4, pp. 246-258.

AIREY, D. y CHONG, K. (2011): Tourism in China: Policy and development since 1949. Routledge. Londres, $352 \mathrm{pp}$.

AIREY, D. y RUHANEN, L. (2014): «Tourism Policy-Making in Australia: A National and State Perspective», Tourism Planning \& Development, vol.11, n 2, pp. 149-162.

ALMEIDA-GARCIA, F. (2014): «A comparative study of the evolution of tourism policy in Spain and Portugal», Tourism Management Perspectives, $\mathrm{n}^{\circ} 11$, pp. 34-50.

BRAMWELL, B. (2011): «Governance, the state and sustainable tourism: a political economy approach», Journal of Sustainable Tourism, vol. 19, n 4-5, pp. 459-477.

CHANG, T.C. (1997): «From 'Instant Asia' to 'multi-faceted jewel': urban imaging strategies and tourism development in Singapore», Urban Geography, vol. 18, n 6, pp. 542-562.

CHANG, T.C. y HUANG, S. (2005): «'New Asia-Singapore': A concoction of tourism, place and image», en Seductions of Place: Geographical Perspectives on Globalization and Touristed Landscapes. Routledge. Londres y Nueva York, pp. 260-275.

DREDGE, D. y JAMAL, T. (2015): «Progress in tourism planning and policy: A poststructural perspective on knowledge production», Tourism Management, $\mathrm{n}^{\circ}$ 51, pp. 285-297.

DREDGE, D. y JENKINS, J. (2007): Tourism Planning and Policy. Wiley. Milton, 504 pp.

DREDGE, D., JENKINS, J. y WHITFORD, M. (2011): «Tourism Planning and Policy: Historical Development and Contemporary Challenges», en Stories of practice: tourism policy and planning. Farnham. Ashgate, pp. 13-55.

DYE, R.T. (2008): Understanding Public Policy. Pearson/Prentice Hall. Englewood Cliffs, $368 \mathrm{pp}$.

EASTON, D. (1965): A System Analysis of Political Life. Wiley. Michigan, 507 pp.

ERN, T., YEOH, B., y WANG, J. (Eds.) (2002): Tourism management and policy: Perspectives from Singapore. World Scientific. Singapur, 368 pp. 
FAYOS-SOLÁ, E. (1996): «Tourism policy: A midsummer night»s dream?», Tourism Management, vol. 17, $\mathrm{n}^{\circ}$ 6, pp. 405-412.

FINANCE MINISTRY TO HANDLE TOURISM (23 de enero de 1963), The Straits Times, p.6.

GANGULI, S. y EBRAHIM, A.H. (2016): «A qualitative analysis of Singapore's medical tourism competitiveness», Tourism Management Perspectives, $\mathrm{n}^{\circ} 21$, pp. 74-84.

HALL, C.M. (1994): Tourism and Politics: Policy, Power and Place. Wiley. Chichester, $238 \mathrm{pp}$.

HALL, C.M. (2000): Tourism planning, policies, processes and relationships. Pearson Hall. Harlow, 302 pp.

HALL, C.M y JENKINS, J.M. (1995): Tourism and Public Policy. Routledge. Londres y Nueva York, 116 pp.

HALL, C.M y OEHLERS (1999): «Tourism and Politics in South and Southeast Asia: Political instability and policy», en Tourism in South and Southeast Asia: Issues and Cases. Butterworth-Heinemann. Londres, pp. 77-93.

HENDERSON, J.C. (2005): «Planning, Changing Landscapes and Tourism in Singapore», Journal of Sustainable Tourism, vol. 13, n 2, pp. 123-135.

HENDERSON, J.C. (2007): «Managing the planning and development of new visitor attractions: a Singapore model». Managing Leisure: An International Journal, vol. $12, n^{\circ} 1$, pp. 24-42.

HENDERSON, J.C. (2014): «Tourism and development in Singapore», en Tourism as an Instrument for Development. Emerald. Bingley, pp. 169-182.

HENDERSON, J.C. (2015): «Destination development and transformation: 50 years of tourism after independence in Singapore», International Journal of Tourism Cities, vol. $1, n^{\circ} 4$, pp. $269-281$.

HENG, T.M y LOW, L. (1990): «Economic Impact of Tourism in Singapore», Annals of Tourism Research, ${ }^{\circ} 17$, pp. 246-269.

KHAN, H., SENG, C.F. y CHEONG, W.K. (1990): «Tourism multiplier effects on Singapore», Annals of Tourism Research, vol. 17, n 3, pp. 408-418.

LAWRENCE, M. y DREDGE, D. (2007): «Tourism planning and policy processes», en Tourism planning and policy. Wiley. Milton, pp. 191-224.

LEE, K.Y. (2000): From Third World to First: The Singapore Story 1965-2000. Times Media Private Limited. Singapur, $830 \mathrm{pp}$.

LEE, P. (2004): Singapore, Tourism \& Me. Pamelia Lee Pte Limited. Singapur, 256 pp.

LEONG, L. (1997): «Commodifying Ethnicity. State and Ethnic Tourism in Singapore», en Tourism, Ethnicity, and the State in Asian and Pacific Societies. University of Hawai'i Press. Honolulu, pp. 71-98.

NATIONAL ARCHIVES OF SINGAPORE (1964): «Speech by the Finance Minister Dr. Goh Keng Swee at the premise of the Tourist Promotion Board Office on 20/5/64 at 5.30pm». National Archives of Singapore. Singapur.

NATIONAL LIBRARY BOARD (2015): «Singapore Tourism Board». Recuperado de: http://eresources.nlb.gov.sg/infopedia/articles/SIP_31_2005-01-31.html

OOI, C. (2001): «Decoding and manufacturing cultures: interpreting Singapore for tourists», CAUSE: A Journal of Philology, n 24, pp. 617-635. 
OOI, C. (2002): «Contrasting strategies: tourism in Denmark and Singapore», Annals of Tourism Research, vol. 29, no 3, pp. 689-706.

PFORR, C. (2005): «Three Lenses of Analysis for the Study of Tourism Public Policy: A case from Northern Australia», Current Issues in Tourism, nº 8, pp. 323-343.

RICHTER, L. K. (1989): The politics of tourism in Asia. University of Hawai'i Press. Honolulu, 263 pp.

SCOTT, N. (2011): Tourism policy: A strategic review. Goodfellow Publishers. Oxford, 64 pp.

SOH, T.K. (August 9 ${ }^{\text {th }}$ 1972): «Many faces of Singapore's transformation», The Straits Times, p.17.

STEVENSON, N., AIREY, D. y MILLER, G. (2008): «Tourism policy making: the policymakers' perspectives», Annals of Tourism Research, vol. 35, nº 3, pp. 732-750.

STB. (1998): A Renaissance City in New Asia-Singapore. Singapore Tourism Board Annual Report 1997/1998. Singapore Tourism Board. Singapur.

STB. (1999): New Millenium, New Momentum, New-Asia Singapore. Singapore Tourism Board Annual Report 1998/1999. Singapore Tourism Board. Singapur.

STB. (2000): Tourism 21. Status Review. Singapore Tourism Board. Singapur.

STB. (2006): Uniquely transforming to greater heights. Singapore Tourism Board Annual Report 2005/2006. Singapore Tourism Board. Singapur.

STB. (2009): Seizing opportunities. Building our future. Singapore Tourism Board Annual Report 2008/2009. Singapore Tourism Board. Singapur.

STB. (2013a): An on-going journey towards quality tourism. Singapore Tourism Board Annual Report 2012/2013. Recuperado de: https://www.stb.gov.sg/news-and-publications/publications/Documents/stb_ar_2013.pdf

STB. (2013b): Navigating the next phase of tourism growth. Tourism Industry Conference. Recuperado de: http://www.yoursingapore.com/content/dam/MICE/Global/bulletinboard/travel-rave-reports/Navigating-the-next-wave-of-Asias-Tourism.pdf

STB. (2014a): Tourism fifty 1964-2014. Singapore Tourism Board Annual Report 2013/2014. Recuperado de: https://www.stb.gov.sg/news-and-publications/publications/Documents/STB_Annual_Report\%202013\%202014.pdf

STB. (2014b): Tourism Industry Conference 2014. Recuperado de: https://www.stb.gov. sg/news-and-publications/lists/newsroom/dispform.aspx?ID=496

STPB. (1979): Singapore Tourist Promotion Board Annual Report. Singapore Tourist Promotion Board. Singapur.

STPB. (1984a): Singapore Tourist Promotion Board Annual Report. Singapore Tourist Promotion Board. Singapur.

STPB. (1984b): Report of the Tourism Task Force. Singapore Tourist Promotion Board. Singapur.

STPB. (1987): Singapore Tourist Promotion Board Annual Report. Singapore Tourist Promotion Board. Singapur.

STPB. (1996): Tourism 21: Vision of a Tourism Capital. Singapore Tourist Promotion Board. Singapur.

TEO, P. y CHANG, T.C. (2000): «Singapore: Tourism development in a planned context», en Tourism in South and Southeast Asia: Issues and Cases. Butterworth-Heinemann, Londres, pp. 117-128. 
TEO, P. y HUANG S. (1995): «Tourism and heritage conservation in Singapore», Annals of Tourism Research, vol. 22, n 3, pp. 589-615.

THE STRAITS TIMES SAYS...WISH YOU WERE HERE (September 30th 1983), The Straits Times, p.18

THE TEN-YEAR PLAN (March 7th 1981), Business Times, p. 7.

VELASCO GONZÁLEZ, M. (2011): «La política turística. Una arena de acción autónoma», Cuadernos de Turismo, no 27, pp. 953-969.

WONG, P.P. (1988): «Singapore: Tourism Development Plans», Tourism Management, vol. $9, \mathrm{n}^{\mathrm{o}} 1$, pp. 73-76. 
